\title{
THE PLACE OF MODERNITY: GERMAN ENTREPRENEURSHIP IN WESTERN SIBERIA IN THE LATE 19TH - EARLY 20TH CENTURIES
}

\author{
Ivan I. Krott \\ Omsk State Pedagogical University. Omsk, Russia. Email: ivkrott[at]mail.ru
}

\begin{abstract}
The study focuses on the issues related to the process of adaptation and economic behavior of German entrepreneurship in Western Siberia in the late 19th - early 20th centuries. The construction of the Siberian Railway and migration processes changed the economy, social structure and cultural practices of "old" Siberia. The "yesterday's outskirts" became a "place of modernity". The paper aims at presenting economic practices and strategies of German entrepreneurship adaptation in the conditions when the socio-spatial structures of the imperial periphery. were experiencing transformation. On the basis of representative resources, the mechanisms and methods of German entrepreneurs' adaptation to the local community are shown. The structure of the market space and its segmentation as well as economic niches and economic strategies of German entrepreneurship are defined. The author comes to the conclusion that German entrepreneurs acted in the region as a "market ferment" changing Siberian society, and they could be regarded as actors of socio-economic, cultural modernization of the Siberian space. At the same time, the German merchants themselves experienced external influence from the host society. The research is based on the combination of macroanalytical strategies and microhistorical approach. The concept of "entrepreneurial minority" is a methodological basis for the study presented in the paper. The materials of the paper are addressed to the experts in the field of the history of Siberia as well as to the professional corporation of the researchers interested in the history of ethnic entrepreneurship and in the issues of various ethnic groups' adaptation to the conditions of a non-ethnic host environment.
\end{abstract}

\section{Keywords}

German Entrepreneurship; "Entrepreneurial Minority"; Western Siberia; Siberian Railway; Adaptation; Host Society; Non-Ethnic Environment; Imperial Periphery; Social Space; Socio-Cultural Transformations 


\title{
МЕСТО «МОДЕРНА»: НЕМЕЦКОЕ ПРЕДПРИНИМАТЕЛЬСТВО В ЗАПАДНОЙ СИБИРИ В КОНЦЕ ХІХ - НАЧАЛЕ ХХ ВВ.
}

\author{
Кротт Иван Иванович \\ Омский государственный педагогический университет. Омск, Россия. Email: ivkrott[at]mail.ru
}

\section{Аннотация}

Исследование сфокусировано на рассмотрении вопросов адаптации и экономического поведения немецкого предпринимательства в Западной Сибири в конце XIX - начале XX в. Сооружение Сибирской железной дороги и миграционные процессы изменили экономику, социальные структуры, культурные практики «старой» Сибири. «Вчерашняя» окраина стала «местом модерна». Цель данной статьи - раскрыть экономические практики и стратегии адаптации немецкого предпринимательства в условиях трансформации социальнопространственных структур имперской окраины. На основе репрезентативных источников раскрыты механизмы и способы адаптации предпринимателейнемцев в локальном сообществе, исследуется структура рыночного пространства, его сегментирование, определены экономические ниши, хозяйственные стратегии немецкого предпринимательства. Автором делается вывод, что предприниматели-немцы выступали в регионе в качестве «рыночного фермента», меняющего сибирское общество, они были акторами социальноэкономической, культурной модернизации сибирского пространства. В то же время коммерсанты-немцы сами испытывали внешнее воздействие со стороны принимающего социума. Исследование строится на сочетании макроаналитических стратегий и микроисторического подхода. Методологической основой выступает концепция «предпринимательского меньшинства». Статья рассчитана на специалистов по истории Сибири, профессиональную корпорацию исследователей истории этнического предпринимательства, процесса адаптации представителей различных этнических групп к условиям иноэтничной принимающей среды.

\section{Ключевые слова}

немецкое предпринимательство; «предпринимательское меньшинство»; Западная Сибирь; Сибирская железная дорога; адаптация; принимающее общество; иноэтничная среда; имперская окраина; социальное пространство; социокультурные трансформации

Это произведение доступно по лицензии Creative Commons «Attribution» («Атрибуция») 4.0 Всемирная 


\section{ВВЕДЕНИЕ}

В результате строительства «большой технической системы» железнодорожной магистрали и «демографической инженерии» в условиях миграционной волны в конце XIX - начале XX вв. имперская «окраина» - Западная Сибирь, - переживала процесс трансформаций социально-пространственных и экономических структур. Общим знаменателем этих масштабных изменений было развитие капиталистических отношений, «включение» местного хозяйства в систему всероссийских и международных рыночных отношений, новую реальность регулирования социально-экономических практик. «Вчерашняя» окраина стала «местом модерна», «пространством будущего». В этих условиях в составе местных деловых кругов, наряду с русскими, активную роль стали играли иностранцы - англичане, датчане, американцы, евреи, немцы. Названные группы предпринимателей приезжали в регион как из Европейской России, так и из-за рубежа.

Важным аспектом истории сибирского предпринимательства является проблема адаптации иностранных предпринимателей к новым для себя экономическим и социокультурным условиях. В целом вопросы адаптации мигрантов в инонациональной среде являются чрезвычайно актуальными и представляют немалый практический интерес в современных условиях. На Западе такого рода исследования стали достаточно традиционными, и соответствующая дискуссия уже имеет историю. В российском профессиональном историческом сообществе проблемы собственно этнического предпринимательства, связи мигрантской экономики с этничностью и создание этнических предпринимательских сетей в автохтонной среде стали рассматриваться совсем недавно. При этом в имеющейся литературе об этническом предпринимательстве уделяется явно недостаточное внимание региональным исследованиям, что, несомненно, обедняет общероссийскую картину. На данном этапе приходиться констатировать, что обширный и весьма интересный сибирский материал, отражающий формирование и функционирование мигрантской экономики, связь предпринимательских сетей с этничностью, характеризующий взаимодействие этнического предпринимательства с принимающим большинством недостаточно изучен и мало введен в научный оборот.

В данной публикации мы рассмотрим экономические практики и стратегии адаптации немецкого предпринимательства, которое достаточно динамично развивалось в Сибири в конце XIX - начале XX вв., 
обозначим контуры его восприятия в условиях трансформации существующих социально-прострнственных структур в рамках инфраструктурной модернизации.

\section{ИСТОЧНИКИ И МЕТОДЫ}

Данное исследование строится с учетом тесного взаимодействия не только различных наук, выражающегося в принципе междисциплинарности, но и различных исследовательских направлений и историографических жанров.

Социокультурная методология работы предполагает раскрытие сферы взаимодействия культуры и социальных отношений, фокусируя внимание на области их взаимовлияния. Многофакторность модернизационной парадигмы наиболее очевидно проявляется тогда, когда предмет исследования «синтетический», в котором заложено взаимодействие, взаимовлияние и взаимозависимость разнохарактерных процессов.

Кроме того, мы активно используем теорию «предпринимательских меньшинств». Названный подход, безусловно, интересен тем, что позволяет рассмотреть проблемы, связанные с участием инонациональных меньшинств в модернизационных преобразованиях, проследить динамику формирования новых социально-экономических отношений, новых форм социального пространства окраины империи на фоне изменений, происходивших в местных обществах. Избранный нами теоретический подход к проблеме не является новым для профессионального исследовательского сообщества. В зарубежном научном дискурсе значимый вклад в изучение предпринимательских меньшинств внесли Э. Геллнер, Э. Бонасич, Д. Хоровиц, Дж. Фэрниволл и др. В отечественной историографии эта тема возникла совсем недавно. Тем не менее, работы В. И. Дятлова, В. Ю. Рабиновича могут рассматриваться как вполне удачные практики, описывающие место и роль предпринимательских меньшинств в принимающем обществе (Дятлов, 2000; Рабинович, 2002).

Исследование также предполагает сочетание макроаналитических стратегий и микроисторического подхода. Макроистория позволяет показать социальные и этнические группы в условиях модернизации, выделить общие ментальные основания, раскрыть специфику общественно-исторического развития России и сибирского региона. Микроистория концентрирует внимание на ментальных установках и стратегиях поведения отдельных представителей этнических групп, что позволяет избежать чрезмерной социологизации истории, сопоставить индивидуальное и коллективное сознание. 
В рамках настоящей работы используется широкий круг репрезентативных исторических источников, включающий как опубликованные, так и архивные документы, многие из которых в научный оборот вводятся впервые.

\section{ОБСУЖДЕНИЕ}

В российской и региональной историографии история сибирских немцев конца XIX - начала XX в., в целом тема немецкого предпринимательства долгое время не имела самостоятельного значения и рассматривалась почти исключительно в контексте более широких проблем по изучению истории сибирского общества - колонизации региона и роли иностранного капитала, состава этих процессов, способов организации, а главным образом, их роли в развитии имперской и сибирской экономик. Следствием такого подхода было преимущественное внимание профессионального сообщества историков к экономическим и экономико-политическим сторонам темы. Приоритетными направлениями в исследованиях считалась аграрная проблематика, история буржуазии и промышленного освоения края, история общественного движения в регионе.

В конце XX столетия в сибирской историографии наметились новые подходы, отражающие интерес к социокультурной и локальной истории. Особое внимание стало уделяться проблемам истории предпринимательства, адаптации мигрантов из Европейской России и дальнего зарубежья к региональным условиям жизнедеятельности, взаимодействию с местным сибирским населением.

В 1994-1999 гг. в связи с подготовкой «Краткой энциклопедии по истории купечества и коммерции Сибири», а также энциклопедии «Предприниматели Алтая», сибирские историки проделали большую работу по сбору информации об иностранных предпринимателях, в том числе и немецких, подготовив более десятка их коммерческих биографий (Резун \& Терешков, 1994-1999; Скубневский, Старцев \& Гончаров, 1996).

В 2001 г. в научном издании «Сибирская заимка» была опубликована весьма актуальная для изучения проблемы адаптации иностранцев в Сибири статья Е.-М. Столберг о сибирском фронтире (Stolberg, 2001).

В этот период развития национальной историографии немцы региона, наряду с другими этническими меньшинствами, оказались в фокусе исследовательского интереса. Здесь можно отметить научный труд П.П. Вибе, посвященный анализу социально-экономической жизни немецких поселений в Сибири (Вибе, 2007). 
В.Н. Шайдуровым также была опубликована работа, в которой он подробно рассмотрел вопросы, связанные с переселением и адаптацией немцев-колонистов в регионе (Шайдуров, 2003).

Несомненно, следует выделить обобщающую монографию Е. В. Карих, в которой автор проанализировал динамику межэтнических отношений на материалах Западной Сибири в процессе хозяйственного освоения региона в XIX - начале XX вв. (Карих, 2004).

В связи с возросшим интересом к адаптации представителей различных этнических групп к условиям иноэтничной принимающей среды в условиях модернизации сибирского общества в конце XIX - начале XX вв. появились специальные исследования, посвященные истории немецкого предпринимательства. Активно работающими авторами в данном направлении являются В. А. Скубневский (Скубневский, 2010), П. П. Вибе (Вибе, 2007), В. Н. Шайдуров (Shaidurov, 2017), А. Г. Киселев (Киселев, 2008), И. И. Кротт (Кротт, 2009; 2010; 2014). Названные историки показали роль немцев в развитии как аграрного, так и промышленного предпринимательства. При этом полем их исследовательских техник стала организация дела, структура капитала, рыночные стратегии и поведенческие практики, социокультурная среда и обычаи.

В целом в современной историографии накоплен большой фактический материал по истории немецкого предпринимательства в Сибири, проработаны вопросы происхождения, численности, состава, форм деятельности, социокультурного облика, внутрисемейных отношений и повседневной жизни.

Использование новых методологических подходов, новых источников, усиление информационной отдачи уже имеющихся источников в последние годы позволило пересмотреть и углубить представления о роли иностранных предпринимателей в жизни сибирского региона.

Но следует обратить внимание, что сегодня нуждается в продолжении работа как по сбору справочно-биографической информации о немцах в Сибири, так и работа по публикации источников, в частности уникальных эго-документов, авторами которых являются выходцы из немецких деловых кругов. Безусловный интерес сохраняет и тема социокультурной адаптации немцев, как российских, так и иностранных подданных, в локальном сибирском сообществе.

\section{В «НОВУЮ АМЕРИКУ»}

Проведение Сибирской железной дороги и массовая аграрная колонизация «открыли» регион для капитализма, создав Сибири 
репутацию «новой Америки». Усовершенствование инфраструктуры, благоприятная рыночная конъюнктура - все это в немалой степени способствовало развитию деловой активности населения как имперского «центра», так и локального сообщества.

Железная дорога сделала Сибирь «интересной», о ней стали писать как иностранцы, в частности англичанин Г. де Виндт, американец Д. Ф. Фразер, канадец К. Оланьон, немец А. Глейнер (Кротт, 2018), так и русская журнальная пресса (Родигина, 2006). Первые транслировали устоявшийся образ Сибири, для которого были характерны «необъятные пространства», «суровая природа», «плохие дороги», «похожие на большие деревни сибирские города», «архаика» в организации своего дела и торговли.

Русской журнальной прессой, имперской создавался образ Сибири как территории «малоизвестной», как региона «чиновничьего произвола», места «каторги и изгнания».

Но со временем публицистический дискурс изменился; по утверждению Н.Н. Родигиной, авторы активно стали использовать метафору «пробуждение ото сна» (Родигина, 2006, с. 124).

Изменение «места Сибири» было связано со строительством и использованием железной дороги, которая стала символом наступления «нового» времени, когда экономика, социальные структуры, культурные практики «старой» Сибири оказались в состоянии радикальной трансформации.

«Преображение Сибири» проявлялось не столько в промышленном развитии, для которого недоставало ряда условий, сколько в разложении традиционных социально-экономических, социокультурных устоев, обыденного сознания и поведения человека. Одновременно с этим происходил процесс становления и развития нового уклада, формирования новых моделей и практик поведения. Железная дорога «все перевернула», появились «новые люди», знания, промыслы, «новые» капиталы. Сибирь стала территорией, где явления экстенсивного, традиционного сосуществовали с явлениями интенсивного, рационального порядка, которые легко «укоренялись» в экономической, шире - социокультурной действительности, что объясняется, главным образом, быстрым развитием в регионе «железнодорожной эпохи» новых социально-пространственных структур (Кротт, 2018).

На рубеже веков полоса вдоль Сибирской железнодорожной магистрали, с одной стороны, сама испытывала влияние и была открыта для «европейских» инноваций, идущих как из стран Западной Европы или Америки, так и Европейкой России, с другой - сама стала 
своеобразным местным «центром» распространения нововведений в национальные районы, «медвежьи уголки» региона: тобольский север, киргизский край и др. В итоге именно данная территория играла роль своеобразного посредника, не только транслируя, но и трансформируя знания и технологии.

Современники неоднократно обращалось внимание на активное участие немецких мигрантов в экономической жизни Сибири, особенно в период после ввода в эксплуатацию железнодорожной магистрали. При этом роль «рыночного фермента», «энергичного элемента» выполняли не только немецкие коммерсанты, выступавшие в качестве самостоятельных предпринимателей, комиссионеров, но и доверенные лица, управляющие региональных отделений иностранных и российских фирм, а так же крупные немецкие сельские хозяева и даже колонисты. В целом можно констатировать, что в этот период в сибирском локальном сообществе имело место широкое распространение предпринимательство немцев, подданных Российской империи, и экономическая деятельность германских торговопромышленных фирм и компаний.

\section{ДЕЛОВЫЕ ПРАКТИКИ «СИБИРСКИХ» НЕМЦЕВ}

Имея большой массив разноплановых источников, можно систематизировать деловые практики немцев-предпринимателей в Западной Сибири, выявить национально-культурную спецификиу их стратегий поведения. Отметим, что, по мнению И. И. Левина, известного специалиста в области иностранных инвестиций в позднеимперскую российскую экономику, современника описываемых процессов, из Германии в Россию эмигрировали не только капиталы, но и деловые люди.

«Немец ... не колонизатор, но и не рабочий, он - Mittelstandsausländer ...

Германия посылает предпринимателей, крестьян, ремесленников, агентов, торговцев и т.д.» (Левин, 1918, с. 48).

Немецкое предпринимательство, как иностранных подданных, так и подданных российской империи, в Западной Сибири можно разделить на четыре группы.

Первой, наиболее многочисленной группой, были торговцы сельскохозяйственными машинами и орудиями, а так же экспортеры масла. Сибирские отделения крупных акционерных обществ «Р. и Т. Эльворти», «Н. Феттер и Гинкель», «Янцен, Нейфельд», «Лепп и Вальман», «Ф.Ф. Шеффер с братьями», «А. Я. Кнопп» торговали усовершенствованным сельскохозяйственным инвентарем. Торговые 


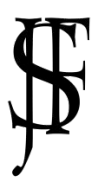

Журнал Фронтирных Исследований. 2021. No 4 | ISSN: 2500-0225

Этнические меньшинства в контактных зонах | Doi: https://doi.org/10.46539/jfs.v6i4.340

дома «Паллизен», «Беккер», «Якоби», «Братья Зейферт» вели операции с сибирским маслом (Оланьон, 1903, с. 120).

К числу предпринимателей данной группы относились и отдельные коммерсанты, операции которых были локализованы в каком-либо одном экономическом районе и связаны преимущественно с маслом (Г. Мюнх - Барнаул, Бийск, Омск и Курган, П. К. Гаст - Барнаул, Э. Ф. Крюгер - Татарск, Барнаул, В.Э. Штенгруббе - Омск) (Скубневский, Старцев \& Гончаров, 1996, сс. 47,62,74; Акишин \& Башкатова, 1999, с. 42).

Вторую группу составляли промышленники, которых было совсем мало. Это Р.И. Крюгер, открывший пивоваренный завод в Томске; это также пивовары братья В. и Р. Елинек в Новониколаевске, Г. Г. Шульц, эксплуатировавший типографию и переплетную мастерскую в Омске, Ф.Ф. Поль, имевший электротехническую мастерскую и электростанцию в том же Омске, владельцы современных мельниц Барнаульского уезда Я. Н. Тьярт и Ф. Вибе (Зашибина \& Киселев, 1996, сс. 70-71; Скубневский, Старцев \& Гончаров, 1996, сс. 27, 51; Зуева \& Скубневский, 1995, с. 112).

Третья группа объединяла немецких коммерсантов в сфере услуг. В этом сегменте предпринимательства в Томске оперировали Н. Грених, Р. Трауб, К. Штамм, А. Фильберт, Э. Фельзенмайер, К. А. Лейнгард, И. И. Шерцингер и О. В. Шмидт (кондитерское, булочное производство, гастрономическая торговля и бакалея, ювелирные, часовые и музыкальные мастерские) (ГАТО, n.d.a, лл. 1-3; ГАТО, n.d.b, лл. 86, 119-121, 125, 152, 195, 202, 236; Из истории российскогерманских отношений: томский фрагмент. Сборник документов и материалов, 2006, с. 38). О.Г. Нольте в Омске организовал крупнейший в регионе технический магазин, где можно было приобрести и заказать все необходимое для строительства или переоборудования промышленного предприятия: от строительных материалов (цемента, асбеста и др.) до локомобилей и динамо-машин. При магазине действовала техническая контора, оказывающая проектно-консультационные и ремонтно-наладочные услуги (ГУ Ис, n.d.a, лл. 1-5; Весь Омск. Справочник-указатель на 1912 год, 1912, сс. 105-116).

Немецкое сельскохозяйственное предпринимательство, составлявшее четвертую группу, сочетало аграрное производство с торговопосреднической деятельностью. Среди крупных сибирских немецких сельских предпринимателей можно назвать хозяйства барона В. Р. Штейнгеля, Ф.Ф. Штумпфа, братьев Г. И. и Я. И. Шварц, А. Ф. Гехтеря, Ф.И. Матиса в Акмолинской области, И. Ф. Вибе, Д. Н. Дика, К.К. Эзау, Р.Г. Шпехта, Н.Я. Классена в Тобольской губернии, 
Я. Н. Корниса в Томской губернии (Вибе, 2007, сс. 99-122; Кротт, 2010, cc. 77-95).

Представителям немецкого предпринимательства отводилась очень важная специфическая роль в экономической и социальной системе принимающего общества, роль «предпринимательских меньшинств». Они занимали экономические сферы, границы которых устанавливали местные традиции, обычаи, сложившаяся система разделения труда.

Выбор подобных экономических ниш стал для немецких предпринимателей во многом и вынужденным шагом. Найденная специализация оказалась, с одной стороны, единственно возможной из-за специфики сибирского края, с другой - она обеспечивала предпринимателям быструю прибыль, включенность в общественные структуры, надежные связи с различными социальными слоями и этническими группами принимающего общества (Кротт, 2014).

Адаптационные стратегии немецких мигрантов в Западной Сибири были различны. Сельские немцы, оказавшись в весьма разнородном социокультурном окружении, стремились к изоляции от местного населения и других мигрантов. Немецкие колонисты, среди которых были и крупные фермерские хозяйства, своими поведенческими практиками подчеркивали обособленность от инонациональной и инокультурной окружающей среды. Это проявлялось в широком распространении моноэтничных немецких поселений и немецкого языка как средства бытового и культурного общения.

Процесс социокультурной адаптации городских немцев имел определенные отличия. В условиях городской среды, которая не создавала возможностей для изоляции, немцы чувствовали себя этноконфессиональным меньшинством, а это способствовало активным контактам с окружающим обществом. В итоге стратегии адаптации городских немцев были близки к интеграции, когда происходило сохранение собственного культурного наследия в сочетании с благожелательным отношением к культуре большинства.

Сельские и городские немцы, как пришлые «чужаки», вынуждены были стремиться быть нужными как можно большему числу членов принимающего общества, ориентироваться на быстрый оборот капитала и «скоростные» хозяйственные операции. Западная Сибирь остро нуждалась в развитии сельского хозяйства, промышленности и торговли, поэтому предприниматели-немцы обосновались в регионе как представители сельскохозяйственной и торгово-промышленной части регионального предпринимательского сообщества. 
Современные исследовательские практики указывают на то, что немецкое предпринимательство занимало на региональном рынке несколько основных ниш, под которые выстраивались их деловые стратегии. Первая - производство и реализация этнических потребительских товаров для нужд их собственных общин (простейшие сельскохозяйственные орудия труда, шерстяные, обувные и столярные изделия). Вторая ниша связана с поставкой этнических товаров для местного населения (немецкая деревянная мебель, колбасные и хлебобулочные изделия). Третья - удовлетворение местных потребностей в разного рода услугах (рынок проектно-консультативных и ремонтноналадочных услуг, мануфактурно-бакалейно-галантерейные заведения). Четвертая ниша предполагала заполнение слабо защищенных и неустойчивых рынков (рынок зерна и земледельческих машин, оборудования для мельниц и маслодельных заводов, рынок электрического оборудования) (Зашибина \& Киселев, 1996, сс. 63-78; Вибе, 2007, cс. 99-122).

Степень инкорпорированности коммерсантов-немцев в региональное экономическое сообщество была очень высока. Они были представлены во многих общественных организациях, тесно связанных с экономикой края (ГУ Ис, n.d.b, л. 2; Зашибина \& Киселев, 1996, с. 74). Более того, изучая немецкое предпринимательство в Западной Сибири, исследователи начала XX в. говорили о нем как о «проникнутом новыми предпринимательскими началами» (Зефиров, 1914, с. 2). В этом отношении немецкие коммерсанты оправдали ожидания имперских экспертов. Известный знаток русского коммерческого мира И. Х. Озеров писал:

«Немец предприниматель, идя со своим капиталом в Россию, привьет нам и дух предприимчивости, принесет нам энергию, творчество, а в этом мы особенно нуждаемся» (Озеров, 1913, с. 334).

Доказательством того, что эти «начала» получили признательность, свидетельствует также такой существенный факт, как распространение немецкого языка в качестве языка делового общения в г. Омске. В путевых записках о Сибири О. Гебель отмечал, что

«с появлением немцев, немецкий язык в Омске можно было услышать через одного», так необычно он звучал на рыночной площади «среди киргизов с верблюжьими повозками» (Гебель, 2010, сс. 282-283).

А. Г. Киселев, рассуждая об операционном пространстве западносибирского предпринимательства как социокультурном явлении, проанализировал почтово-телеграфную статистику. Его подсчеты 
показали, что в общем массиве деловых телеграмм значительное место в Западной Сибири занимали телеграммы в Германию и из Германии (Киселев, 2008, сс. 172-174).

В то же время важным условием деловой и культурной адаптации было освоение иностранными предпринимателями русского языка. Немецкие коммерсанты вполне хорошо знали русский язык. По наблюдению все того же О. Гебеля, русские немцы в Сибири хорошо говорили по-русски, а для некоторых он был со временем уже как родной (Гебель, 2010, сс. 287,288).

Очевидно, что язык и традиции принимающего социума постигались этническими мигрантами тем легче, чем плотнее и интенсивнее шли их контакты с сибирским населением. Наличие рядом соотечественников, хотя и делало процесс «приживания» на новом месте менее болезненным, но не могло ему не препятствовать. Между соотечественниками «на чужбине» возможны были и конфоликтные ситуации на почве конкуренции, отмеченные тем же О. Гебелем применительно к омским немцам, торговавшим в регионе маслом и машинами (сс. 282).

\section{ВЫВОДЫ}

Западная Сибирь после постройки железной дороги и «демографической инженерии» изменила «материальную форму» пространства, систему регулирования социально-экономических практик. «Вчерашняя» окраина стала «местом модерна», «пространством будущего».

Социокультурная организация сибирского общества открывала для немцев канал вертикальной социальной мобильности в виде предпринимательской деятельности. Приезжающим в Сибирь были свойственны новые, отличные от местных, ментальные представления и хозяйственные практики. Немецкие коммерсанты не потерялись и не растворились в общей миграционной массе, «накрывшей» Сибирь после строительства железной дороги; наоборот, они заняли определенные экономические ниши, играя весьма важную роль в общественном разделении труда. Экономический успех немецкого предпринимательства достигался в Сибири не за счет использования местных форм и обычаев, а, напротив, за счет новаций с учетом российского и нероссийского опыта, хотя, конечно, приспособленных к местным условиям.

В результате своей экономической деятельности немецкие предприниматели стали неотъемлемой частью существовавших в регионе социальных отношений и хозяйственных связей, они стали акторами 
трансформаций социально-пространственных и экономических структур. При этом предприниматели-немцы сохраняли основные этнические черты, традиции, чтили религиозные нормы, охраняя свою этнокультурную самобытность.

Необходимо признать, что каждая из локальных групп немецких предпринимателей действовала относительно автономно - в рамках своего региона, интегрируясь в его экономическую жизнь, приспосабливаясь к местным условиям. Имеющиеся в нашем распоряжении источники отмечают редкие попытки установления межрегиональных контактов по этническому признаку. Вместе с тем знакомство с европейской деловой традицией, знание иностранных языков, партнерские отношения с западноевропейскими «деловыми людьми» давали возможность немецким предпринимателям в Сибири выступать в роли «связующего звена», соединявшего российское и европейское предпринимательство. Несмотря на относительную немногочисленность немецкого предпринимательства в Сибири, оно играло в регионе ведущую роль благодаря своему экономическому влиянию.

«Фронтир» - как подвижная граница «встречи», «место действия» разных моделей и практик хозяйствования, контактов пришлых и коренных, - продолжал присутствовать, но в условиях глубокой трансформации сложившихся экономических, социальнопространственных структур определяющей была роль предпринимателей, «деловых людей», так как именно они и продвигали «границу на окраины».

\section{Список литературы}

Shaidurov, V. (2017). German Industrial Enterprises in Western Siberia in the second half of the 19th century. Bylye Gody, 43(1), 162-168. doi: 10.13187/bg.2017.1.162

Stolberg, E.-M. (2001). Siberia-Russia’s Wild East. Some Notes about Frontierism, 1890-1915. Retrieved from Siberian Zaimka website: https://zaimka.ru/stolberg-frontierism/

Акишин, М. О., \& Башкатова, З. В. (1999). Краткая энциклопедия по истории купечества и коммериии Сибири. Новосибирск: РИПЭЛ-плюс.

Весь Омск. Справочник-указатель на 1912 год. (1912). Омск: Типография «ИРТЫШ».

Вибе, П. П. (2007). Немецкие колонии в Сибири: Социально-экономический аспект. Омск: ООО Издательский дом «Наука».

Гебель, О. (2010). От Урала до Сахалина. В Европейские общцны в российской провинции во второй половине XIX - начале XX в. Сборник научных статей (с. 265-293). Барнаул: АзБука. 
Государственное учреждение Омской области «Исторический архив Омской области». (б. д.-а). Ф. 36. Оп.1. Д. 59.

Государственное учреждение Омской области «Исторический архив Омской области». (б. д.-b). Ф. 199. Оп.. 1. Д. 15.

Государственный архив Томской области (ГАТО). (б. д.-а). Ф. 233. Оn.2. Д. 2066.

Государственный архив Томской области (ГАТО). (б. д.-b). Ф. 129. On. 1. Д. 557.

Дятлов, В. Ю. (2000). Современные торговые меньшинства: Фактор стабильности или конфликта? (Китайцы и кавказцы в Иркутске). Москва: Наталис.

Зашибина, Е. Л., \& Киселев, А. Г. (1997). Немецкие коммерсанты в Омском Прииртышье в начале XX в. В Немщы. Россия. Сибирь. Сборник статей (с. 63-78). Омск: Издательство ОГИК музея.

Зефиров, Н. (1914). Крупные частновладельческие и арендаторские хозяйства в Акмолинской области. Омск: Издательство Переселенческого управления Акмолинской области.

Зуева, Е. А., \& Скубневский, В. А. (1995). Краткая энщиклопедия по истории купечества и коммериии Сибири. Новосибирск: Наука.

Из истории российско-германских отношений: Томский фрагмент. Сборник документов и материалов. (2006). Томск: Красное знамя.

Карих, Е. В. (2004). Межэтнические отношения в Западной Сибири в процессе ее хозяйственного освоения. XIX - начало XX в. Томск: Издательство Томского университета.

Киселев, А. Г. (2008). Фирма на рынках Западной Сибири в конце XIX - начале XX вв. Ханты-Мансийск: Издательство ЮГУ.

Кротт, И. И. (2009). Немецкое предпринимательство в административных центрах Сибири. В П. П. Вибе (Ред.), История и этнография немцев Сибири (сс. 125-13). Омск: Издательство ОГИК музея.

Кротт, И. И. (2010). Сельскохозяйственное предпринимательство: Поведенческие стратегии и практики в условиях трансформации сибирского общества (1914- 1920 г2.). Омск: Издательство ОмГПУ.

Кротт, И. И. (2014). «Чужаки» в условиях иноэтничной среды: Предпринимательство сибирского переселенческого сообщества второй половины XIX - начала XX века. Историческая психология и социология истории, 7(2), 93-108.

Кротт, И. И. (2018). Вчерашняя окраина как место прорыва: Сельскохозяйственное предпринимательство Западной Сибири в конце XIX - начале XX вв. Исторический курьер, (2), 1-21. doi: 10.31518/2618-9100-2018-2-2

Левин, И. И. (1918). Германские капиталы в России. Петроград: Типография И. Шурухта.

Озеров, И. Х. (1913). Что делать? Москва: Универсальное книгоиздательство Л. А. Столярова. 
Оланьон, К. Л. (1903). Сибирь и ее экономическая будущность. Санкт-Петербург: Издательство товарищества «Просвещение».

Рабинович, В. Ю. (2002). Евреи дореволюционного Иркутска: Меняющееся меньшинство в меняющемся обществе. Красноярск: Издательство «Кларетианум».

Резун, Д. Я., \& Терешков, Д. М. (1994-1999). Краткая энциклопедия по истории купечества и коммериии Сибири (Т. 1-4). Новосибирск: РИПЭЛ-плюс.

Родигина, Н. Н. (2006). «Другая Россия»: Образ Сибири в русской журнальной прессе второй половины XIX - начала XX века. Новосибирск: Издательство НГПУ.

Скубневский, В. А. (2010). Немецкое предпринимательство на Алтае во второй половине XIX - начале XX в. Известия Алтайского государственного университета. Серия История, (4-3), 198-202.

Скубневский, В. А., Старцев, А. В., \& Гончаров, Ю. М. (1996). Предприниматели Алтая, 1861-1917: Энщиклопедия. Барнаул: Демидовский фонд.

Шайдуров, В. Н. (2003). Формирование и социально-экономическое развитие немецкой диаспоры на Алтае: Конец XIX - начало XX вв. Барнаул: Полиграф-сервис.

\section{References}

Akishin, M. O., \& Bashkatova, Z. V. (1999). Short Encyclopedia on the History of Merchants and Commerce of Siberia. Novosibirsk: RIPEL-plus. (In Russian).

All of Omsk. Reference book for the year 1912. (1912). Omsk: "IRTYSH" printing house. (In Russian).

Dyatlov, V. Y. (2000). Modern Trade Minorities: A Factor of Stability or Conflict? (The Chinese and Caucasians in Irkutsk). Moscow: Natalis. (In Russian).

From the History of Russian-German Relations: Tomsk Fragment. Collection of documents and materials. (2006). Tomsk: Krasnoye Znamya. (In Russian).

Goebel, O. (2010). From the Urals to Sakhalin. In European Communities in the Russian Province in the Second Half of the 19th and the Beginning of the 20th Centuries. Collection of scientific articles (pp. 265-293). Barnaul: AzBuka. (In Russian).

Karikh, E. V. (2004). Interethnic relations in Western Siberia in the process of its economic development. 19th - beginning of the 20th century. Tomsk: Tomsk University Press. (In Russian).

Kiselev, A. G. (2008). The firm in the markets of Western Siberia in the late nineteenth and early twentieth centuries. Khanty-Mansiysk: YuGU Publishers. (In Russian).

Krott, I. I. (2009). German Entrepreneurship in the Administrative Centers of Siberia. In P. P. Vibe (Ed.), History and Ethnography of the Germans of Siberia (pp. 125-13). Omsk: OGIK Museum Publishing House. (In Russian).

Krott, I. I. (2010). Agricultural Entrepreneurship: Behavioral Strategies and Practices in the Transformation of Siberian Society (1914-1920). Omsk: Omsk State Pedagogical University Press. (In Russian). 
Krott, I. I. (2014). "Strangers" in a Foreign-Ethnic Environment: Entrepreneurship of the Siberian Migratory Community in the Second Half of the 19th and the Beginning of the 20th Centuries. Historical Psychology and the Sociology of History, 7(2), 93-108. (In Russian).

Krott, I. I. (2018). Yesterday's Outskirts as a Breakthrough Site: Agricultural Entrepreneurship in Western Siberia in the Late 19th and Early 20th Centuries. Historical Courier, (2), 1-21. doi: 10.31518/2618-9100-2018-2-2 (In Russian).

Levin, I. I. (1918). German Capitals in Russia. Petrograd: Printing house of I. Shurucht. (In Russian).

Olanyon, C. L. (1903). Siberia and its economic future. St. Petersburg: Publishing house of the association "Prosveshchenie". (In Russian).

Ozerov, I. H. (1913). What to do? Moscow: L.A. Stolyarov Universal Book Publishing House. (In Russian).

Rabinovich, V. Yu. (2002). Jews of pre-revolutionary Irkutsk: A Changing Minority in a Changing Society. Krasnoyarsk: Claretianum Publishers.

Rezun, D. Y., \& Tereshkov, D. M. (1994-1999). Short encyclopedia on the history of merchants and commerce of Siberia (Vol. 1-4). Novosibirsk: RIPEL-plus. (In Russian).

Rodigina, N. N. (2006). "The Other Russia”: The Image of Siberia in Russian Journalism in the Second Half of the 19th and Early 20th Centuries. Novosibirsk: Novosibirsk State Pedagogical University Press. (In Russian).

Shaidurov, V. (2017). German Industrial Enterprises in Western Siberia in the second half of the 19th century. Bylye Gody, 43(1), 162-168. doi: 10.13187/bg.2017.1.162

Shaidurov, V. N. (2003). Formation and Socio-Economic Development of the German Diaspora in Altai: late 19th - early 20th centuries. Barnaul: Polygraph Service. (In Russian).

Skubnevsky, V. A. (2010). German Entrepreneurship in the Altai in the Second Half of the 19th and the Beginning of the 20th Centuries. Proceedings of the Altai State University. History Series., (4-3), 198-202. (In Russian).

Skubnevsky, V. A., Startsev, A. V., \& Goncharov, Y. M. (1996). Entrepreneurs of Altai, 1861-1917: Encyclopedia. Barnaul: Demidov Foundation. (In Russian).

State Archive of the Tomsk Region. (n. d.-a). F. 233. In.2. C. 2066. (In Russian).

State Archive of the Tomsk Region. (n. d.-b). F. 129. In. 1. C. 557. (In Russian).

State Institution of the Omsk Region "Historical Archive of the Omsk Region". (n. d.-a). F. 36. In.1. C. 59. (In Russian).

State Institution of the Omsk Region "Historical Archive of the Omsk Region”. (n. d.-b). F. 199. In. 1. C. 15. (In Russian).

Stolberg, E.-M. (2001). Siberia-Russia's Wild East. Some Notes about Frontierism, 1890-1915. Retrieved from Siberian Zaimka website: https://zaimka.ru/stolberg-frontierism/

Vibe, P. P. (2007). German Colonies in Siberia: Social and Economic Aspect. Omsk: OOO Publishing House "Nauka". (In Russian). 
Zashibina, E. L., \& Kiselev, A. G. (1997). German merchants in the Omsk Priirtyshie at the beginning of the 20th century. In Germans. Russia. Siberia. Collected articles (pp. 63-78). Omsk: OGIK Museum Publishing House. (In Russian).

Zefirov, N. (1914). Large private and tenant farms in Akmola region. Omsk: Publishing house of the Resettlement Department of Akmola Oblast. (In Russian).

Zueva, E. A., \& Skubnevsky, V. A. (1995). A brief encyclopedia on the history of merchants and commerce of Siberia. Novosibirsk: Nauka.. (In Russian). 